\title{
Considering Anomalous Events during Bereavement as Evidence for Survival
}

\author{
Callum E. Cooper
}

\section{Chapter Overview}

It has been noted that experiences of perceived interaction with the dead are common for the bereaved. Surveys have reported that around 50-60\% of individuals will report that they have had such an experience following a significant death. These reports are spontaneous by their very nature and can involve a variety of experiences, from sensing the presence of the dead, to dreaming about them, seeing apparitions in the waking state, witnessing poltergeist type phenomena, and others. Even so, it is acknowledged that instances of alleged reincarnation where a young child may relay information from a deceased individual have been noted, and sought phenomena such as sittings with mediums and therapy induced experiences suggestive of interaction with the dead could produce information pertaining to survival. However, this chapter will focus purely on spontaneous anomalous experiences occurring following loss.

The question remains, what are the ontological roots of such experiences? Mainstream opinions have conceptualized such reports as purely pathological and typical bi-products of a grieving mind. However, is there a case for something more at work? To answer this, we not only need to understand the psychology of bereavement, but indeed the parapsychology of bereavement as well. This chapter will consider the place of anomalous bereavement experiences in the debate of 'consciousness and its survival beyond bodily death' (aka, the survival hypothesis), and what evidence exists from such events which may add weight to the debate and goes beyond current conventional understanding. 


\section{Introduction}

Anomalous experiences can be defined as experiences in which the abilities a person claims to have, or experiences they have, may appear to be non-ordinary to the person having the experience or any witnesses present (see Smith, 2010, p.1) - or to the culture in which they operate. Where conventional explanations don't appear to account for the observed phenomenon, we may speak of the experience as being anomalous in the sense that the processes involved do not seem to be explainable via current scientific paradigms. As the research develops, it is hoped that understanding of such processes should become clear and commonplace within science. Yet, as this chapter shall demonstrate, the features of such experiences - to date - have already been studied in great depth. Anomalous experiences could involve precognitive visions or telepathic dreams, or the witnessing of apparitions, poltergeist type phenomena and a variety of sensory experiences, such as sensing the presence of people who are not physically present. Therefore, in anomalous bereavement experiences, experients typically report a diversity of spontaneous sensory phenomena which they may interpret as interaction and/or communication with significant people who have died. This could include the sense of presence experience, through to hearing the deceased, smelling fragrances associated with the deceased (e.g., perfume or tobacco), feeling their touch, dreaming about them, movements and manipulations of objects associated with them, through to the witnessing of apparitions (see Cooper, Roe \& Mitchell, 2013). The extent to which these experiences actually provide evidence for the survival of consciousness and human personality beyond death is still highly debatable. Even so, we shall discuss some of the key thoughts on the

survival hypothesis within this chapter. Before entering this discussion, some brief consideration will be given to understanding how common such phenomena are among the bereaved, and how well-established the research into such matters has become within the social 
sciences. Thus, it will be demonstrated that parapsychology is firmly engrained within the social scientific community, especially where clinically-oriented parapsychology matters are concerned (Steffen, Wilde, and Cooper, in press).

Anomalous experiences during a time of loss are common events. During the early work of the Society for Psychical Research (est. 1882), a study was conducted to understand the typical features and frequency of anomalous experiences which occurred for the bereaved. Edmund Gurney and Frederic Myers (1889) extracted 211 accounts from the extensive and highly detailed book Phantasms of the Living (see Gurney, Myers, \& Podmore, 1886), where it appeared that anomalous events sometimes occurred following loss. Using an early form of a content analysis, common themes of such experiences and frequencies of their occurrence began to emerge from the accounts. Of these cases, 134 spontaneous anomalous experiences were reported to have occurred within the hour of death, and 29 between 1 and 12 hours after death. (Post-mortem apparitions beyond this time were excluded from Phantasms of the Living.) The researchers commented:

[T] he recognised apparitions decrease rapidly in the few days after death, then more slowly; and after about a year's time they become so sporadic that we can no longer include them in a steadily descending line.

(Gurney with Myers, 1889, p.427)

Frequency of Apparitions Experienced Before and Following Death (Gurney with Myers, 1889, p.427) 


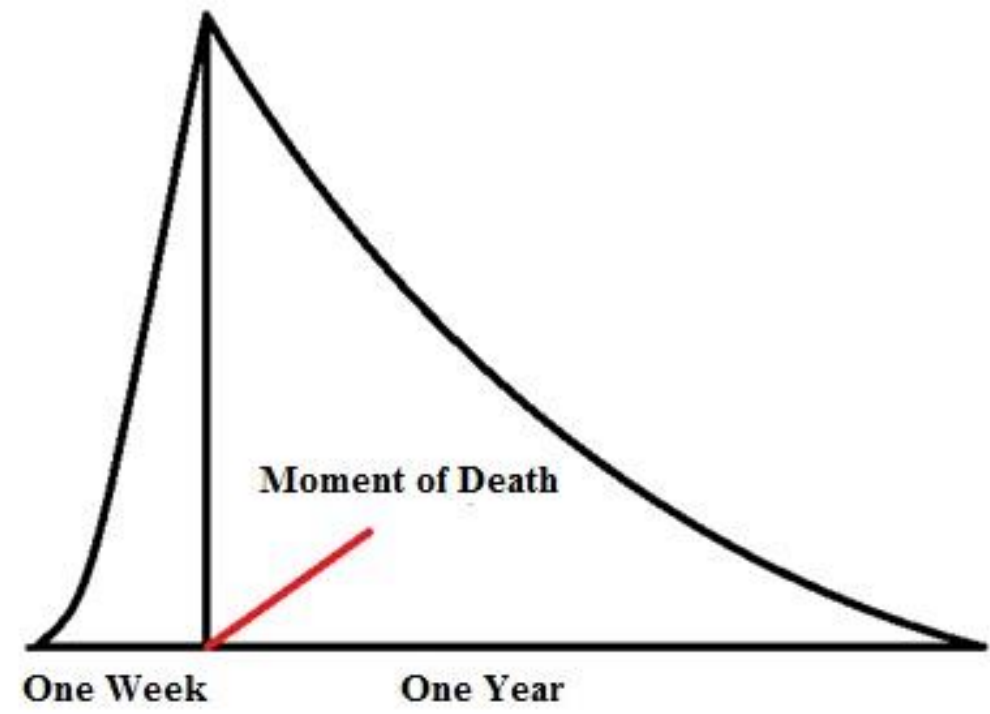

Gurney and Myers were aware that the experience of encountering sensory stimuli associated with that of deceased friends and relatives was common. They were also very aware of many common ill-informed explanations for such experiences, such as "the person was drunk or delusional at the time" or "emotionally excited, and perhaps misinterpreted sights or sounds of an objective kind." They noted that:

A very little careful study of the subject will, however, show that all these hypotheses must be rejected; that the witness may be in good health, and in no exceptional state of nervousness or excitement, and that what he sees or hears may still be of purely subjective origin - the projection of his own brain.

(ibid, pp.403-404)

Their study suggested that there is argument for the hallucination to not be purely subjective if: 1) additional people present also saw the apparition, or 2) the apparition conveyed information only known by the deceased and not by the experient, but is later confirmed to be correct. Many books on bereavement throughout this time simply passed such experiences off 
as pure side effects of grief, and in the Complete Psychological Works of Sigmund Freud (25 volumes) such experiences were simply dismissed in three lines as 'psychotic hallucinations' (see Rees, 2000, p.83).

It could be argued that it wasn't until eight decades later with the publication of a longitudinal study conducted as part of a medical doctorate by Rees (1971), that the experiences began to be taken seriously in the 'main steam'. The study published in the British Medical Journal was entitled 'The hallucinations of widowhood'. The term 'hallucination' was used very loosely, referring to anomalous sensory experiences ranging from a sense of presence, through to: smells, touch, voices, and full visual apparitions of the dead. The participant sample was collected in an area of mid-Wales including 227 widows and 66 widowers, all of whom were interviewed to determine the extent of their experiences during widowhood/bereavement. Upon analysing the data, it was found that the sense of presence of the dead was amongst the most common of experiences occurring in around 39.2\% of cases, while around 13 to $14 \%$ of cases reported visual and auditory hallucinations. In $11 \%$ of cases, the bereaved claimed to have not only experienced the presence of the dead, but also conversed with them and interacted.

The study by Rees (1971) demonstrated not only the commonality of such experiences, but also how beneficial these experiences often are to the bereaved, offering comfort and therapeutic values. Figures of between $50-60 \%$ of the bereaved reporting such phenomena have remained consistent overtime (e.g., Burton, 1982; Castelnovo, et al., 2015). The research has created a noticeable chain reaction of various study replications and alternative approaches, in order to understand in greater depth the therapeutic aid such experiences can bring (Krippner, 2006). In current research, attention has been given to the cognition of hope, and how 
individuals who report such experiences increase in personal health and well-being due to obtaining a greater personal sense of hope for personal life goals and for survival beyond death (Cooper, 2017). Clinical parapsychology has been a key focus of research into anomalous experiences during bereavement since the publication by Rees (1971), that is, in terms of what impact such experience have on our health and well-being, rather than investigating their ontology (e.g., Cooper, 2016; Kramer, Bauer, \& Hövelmann, 2012; Roxburgh, \& Evenden, 2016). With this in mind, let us now give some attention to this matter and consider what aspects of anomalous experiences following personal loss could possibly constitute 'evidence' for survival of human personality beyond bodily death.

\section{Cases of Potential Evidence for Survival}

For cases of spontaneous anomalous experience during bereavement to become of interest to theorists and researchers of survival, we would expect there to be key features of the experience which would suggest something more than a subjective nature and perhaps purely illusory creation (created either consciously or unconsciously due to loss and longing for the deceased's

return) - this is in accordance with the conclusions made by Gurney and Myers (1889). Even though there is a large amount of literature and research, documenting and discussing accounts of anomalous phenomena suggesting survival (to cite but a few: Baird, 1944; Berger, 1988; Betty, 2016; Fontana, 2005; Gurney, Myers, \& Podmore, 1886; McAdams \& Bayless, 1981; Myers, 1903; Robertson, 2013; Rogo, 1986; Thomas, 1929) the case for survival as a whole is far too extensive to discuss in any depth or fair summary in a single book chapter (as previously noted by Gauld, 2005). However, here we are specifically concerned with cases suggesting survival during a period that could be considered bereavement for the experient, which are 
arguably limited within the available literature against other cases suggestive of survival (e.g., experiences prior to the knowledge of loss, mediumship, reincarnation events).

We know that such accounts exist on record, and are reported to occur, but it requires a good deal of searching to identify such cases. This is for two reasons, firstly, survival type phenomena cover a range of experiences, and are not just limited to experiences of the bereaved, and secondly, if these experiences are not reported by experients to the appropriate people and organisations, they never become committed to record and are lost. Some have questioned this as a decline effect in the phenomena itself (e.g. Gauld, 2010). I would go further to argue that it is due to a failure in reporting, which was highly favourable a hundred years ago as psychical research literature demonstrates, and in the early work of the Parapsychology Laboratory at Duke University (see Horn, 2009; Weiner \& Haight, 1986). This is partly caused by issues of the media's negative portrayal of parapsychology and the wider public knowing little about who the professional and reliable researchers are, and how to contact them to report their experiences and have them professionally investigated (see Thomas \& Cooper, 2016; Winsper, Parsons \& O’Keeffe, 2008). ${ }^{*}$ This matter is also closely linked with other professional sciences/scientists knowing little of the research evidence from parapsychology (and openly not wanting to, in some cases), and yet publicly dismissing it out of hand based on personal biases (Fontana, 2007). This is not a credible scientific attitude, and thus, is a poor and unjust approach to science, grossly misleading their audiences. Even so, let us consider some noteworthy cases suggestive of survival that are on public record.

\footnotetext{
${ }^{*}$ For those who believe they have encountered experiences of this kind, please contact the Society for Psychical Research (www.spr.ac.uk). Alternatively, please get in touch with the author of this chapter.
} 
Following Rees (1791), Julian Burton was the next person to complete a doctoral study on the commonality of anomalous experience in bereavement and their characteristics (Burton, 1980). He began this academic attempt to understand such reports after he had such an experience regarding of his own mother, who had died seven months prior to the episode. It was recalled as follows:

I had always felt a strong bond between us but by September most of us in the family had returned to our routines, reconciled to her death. One evening that September my wife and I were entertaining relatives. I was in the kitchen cutting a pineapple when I heard what I thought were my wife's footsteps behind me to the right. I turned to ask the whereabouts of a bowl but realized that she had crossed to the left outside of my field of vision. I turned in that direction to repeat my question and saw my mother standing there.

(Burton, 1982, p.65)

Burton said his mother's apparition looked 10 years younger than she appeared when she died and was in good health; however, she was wearing a detailed pale-blue gown which he had never seen before. He continued:

'Ma!' I exclaimed. She smiled - and then dissolved. She did not disappear; she dissolved. I let out a great sigh and felt as if a heavy weight had been lifted from me, a weight I had not even felt until then.

(ibid, p.65)

The next morning Burton related his experience to his sister who, he said, became upset, not because of the occurrence he described, but largely because she had not had such an experience herself. However, she believed Burton's account because two weeks before their mother's 
death, she had taken their mother shopping, and recalled their mother having tried on a paleblue gown that matched Burton's description. (Their mother didn't buy the gown because the price was too high). Burton's experience confirmed survival of death for both siblings, and established a form of continued bond for Burton, stating that "The experience had a profound effect on me; it encouraged me to make a major change in my life" (p.68). This major change is what pushed Burton back into education to take on a $\mathrm{PhD}$ at the age of 42 , in order for him to understand more about such experiences in the wider population.

Baird (1944) compiled an important collection of cases suggestive of survival encompassing eleven different forms of parapsychological phenomena. Within this, apparitions of the dead were discussed with some falling within the category of 'bereavement type phenomena'. Interestingly, in the majority of experiences, as noted previously in this chapter, the cases involved witnessing an apparition of a deceased person before the experient knew that person to be dead. And yet, the time of the experience coincided with the time of death and veridical information was received by the experient. Even so, below is a classic example from Baird's compilation of the apparition occurring sometime following conscious awareness of the loss. It was originally reported in the Proceedings of the Society for Psychical Research (volume 5), and is summarised here from Baird's (1944) presentation:

In 1867, my older sister, a young lady of eighteen years, died suddenly of cholera in St. Louis, Mo. My attachment for her was very strong, and the blow a severe one to me. A year or so after her death the writer became a commercial traveller, and it was in 1876, while on one of my western trips, that the event occurred.

I had 'drummed' the city of St. Joseph, Mo., and had gone to my room at the Pacific House to send in my orders, which were unusually large ones, so that I was in a very happy frame of mind indeed. My thoughts, of course, were about these orders, knowing how 
pleased my house would be at my success. I had not been thinking of my late sister, or in any manner reflecting on the past. The hour was high noon, and the sun was shining cheerfully into my room. While busily smoking a cigar and writing out my orders, I suddenly became conscious that someone was sitting on my left with one arm resting on the table. Quick as a flash I turned and distinctly saw the form of my dead sister, and for a brief second or so looked her squarely in the face; and so sure was I that it was she, that I sprang forward in delight, calling her by name, and as I did so the apparition instantly vanished. Naturally, I was startled and dumbfounded, almost doubting my senses; but with the cigar in my mouth, and pen in hand, with the ink still moist on my letter, I satisfied myself that I had not been dreaming and was wide awake. I was near enough to touch her, had it been a physical possibility, and noted her features, expression, and details of dress, etc. She appeared as if alive. Her eyes looked kindly and perfectly naturally into mine. Her skin was so lifelike that I could see the glow or moisture on its surface, and, on the whole, there was no change in her appearance otherwise than when alive.

Now comes the most remarkable confirmation of my statement, which cannot be doubted by those who know what I state actually occurred. This visitation, or whatever you may call it, so impressed me that I took the next train home, and in the presence of my parents, and others, I related what had occurred. My father, a man of rare good sense and very practical, was inclined to ridicule me, as he saw how earnestly I believed what I had stated; but he too, was amazed when later on I told them of a bright red line or scratch on the right hand side of my sister's face, which I distinctly had seen. When I mentioned this my mother rose trembling to her feet and nearly fainted away, and as soon as she sufficiently recovered her self-possession, with tears streaming down her face she exclaimed that I had indeed seen my sisters, as no living mortal but herself was aware of the scratch, which she had accidently made while doing dome little act of kindness after my sister's death. She said she well remembered how pained she was to think that she should have unintentionally marred the features of her dead daughter and, unknown to all, how she had carefully obliterated all traces of the slight scratch with the aid of powder, etc., and that she had never 
mentioned it to a human being from that day to this. In proof, neither my father nor any of our family had detected it and positively were unaware of the incident, yet $I$ saw the scratch as bright as if just made.

(quoted by Baird, 1944, p.64-65)

Taking these cases into consideration, and reflecting on my own work with the bereaved who reported spontaneous experiences following loss (Cooper, 2017); some similar features which could meet the criteria of 'possible evidence for survival' do appear present in contemporary cases. To briefly discuss one such incident, the fact of multiple witnesses involved makes the case most intriguing. One participant in my research - a nurse of many years' experience especially with the terminally ill - witnessed the passing of her own husband while sitting by his hospital bed. Jane [pseudonym] reported that immediately her mobile phone began acting irregularly and would not work, which she personally found most peculiar in light of what had just happened. During her husband's illness, he had said that if he did survive beyond death, that he would give her a sign. In the week that followed, a number of unusual events happened in Jane's life especially around the home. A number of electrical disturbances occurred including the electric car windows playing up and not closing, which held personal meaning for Jane (due to discussions and experiences Jane had had with her husband regarding the car before he passed), and sense of presence experiences were encountered (see Wright, 1998, for similar examples of this phenomenon). At the funeral, which took place within two weeks of her husband's passing, Jane reported the following event during interview:

My brother-in-law and his girlfriend sat down at the table with their drinks and they put the girlfriend's drink right on the inside of the table, and the drink proceeded to be pushed off the table and fell on the floor, and the actual glass landed up, it didn't fall it landed actually on the actual base... the drink spilt but the glass didn't smash. 
Jane reported that she did not personally witness this incident, but it was witnessed by her brother-in-law, his girlfriend, and seven other witnesses close by. She immediately went to see what all the commotion was about and was told straight away of what had happened. Her brother-in-law was reportedly lost for how to explain what had been seen, and subsequently became more open minded to the possibility of life after death. The table had been covered with a table cloth, and so the glass could not naturally have slid against the table due to any possible condensation or spillage from the glass. Jane also noted that she had not reported her anomalous experiences prior to that day to anyone. The event at the wake was witnessed by nine people in total, and confirmed for her that these occurrences were objective and signs of her husband's survival from which she gained great comfort.

\section{Thoughts on the Reality of Survival}

It has been argued by Gauld (2005) that it is by no means clear or agreed upon, as to what exactly would constitute evidence for survival of death. Some people are too quick to jump to conclusions of evidence for survival from experiences (and in bereavement events that is understandable on the part of the bereaved), while for other people, no amount of empirical findings would personally convince them of survival. Even though Gurney and Myers (1889) argued that either veridical information or multiple witnesses should be involved to begin to constitute a possible case for survival, extensive debate within parapsychology since that time has cast some doubt over these two features and their potential for providing concrete evidence for survival. 
Burton (1982) commented at the end of his study that "It is certainly interesting, in this regard, that when a person has been contacted, he knows exactly what has happened. He needs no formal 'proof' that he has had a valid experience" (p.73). From a scientific point of view, we require more than this personal interpretation to persuade us of survival being a possibility. It would seem, however, as pointed out by Gurney (with Myers, 1889), that if we apply simple investigation to such common experiences of the bereaved, we can discover the elements of the experience which would suggest survival of death. It is simply a case of considering all avenues of conventional explanations and cautiously applying Occam's razor (MartínezTaboas, 1983; Romer, 1996), to identify the conventional explanations that would apply to the experience that is being perceived as survival. In other words, we would accept the fewest assumptions required as possible to explain the phenomena.

Murphy (1943) proposed the notion of active and passive telepathy against the problem of survival evidence. In short, he stated that if there are apparently no conventional explanations for the phenomena encountered, then we must assume that some form of extra sensoryperception (ESP) is responsible. However, who activates this ESP becomes another question. For example, are the deceased communicating with the living via such means, or is the experience generated by some living agent projecting hallucinations and information about the deceased via some form of ESP? This could even account for instances of multiple witnesses to an apparitional encounter, where one witness has unconsciously created the hallucinatory imagery for everyone else to bear witness via a telepathic process (see Rao, 1986).

Where conventional explanations do not appear to account for the phenomena witnessed, Occam's razor would still lead us to question the presence of ESP, but to support this 
assumption would strongly suggest that the experience is more likely the creation of a living mind, than that of the deceased communicating with the living through telepathic means. The only objection Murphy (1943) could place to this assumption, is that we must ask ourselves who instigated the experience? If a bereaved individual is actively thinking about the deceased, then it is most likely they who generated the experience through some form of cognitive process not yet fully understood. However, if the experient was engaged in a particular task, or conversation with other people, etc., and not actively thinking about the deceased (though there is the possibility of them unconsciously ruminating about the deceased), the possible explanations for such experiences would lead to several possible conclusions, which still leaves some scope for the reality of survival - as none of the conclusions could be empirically confirmed through scientific means, nor indeed disproven. This simply emphasises the difficulties involved in researching and understanding phenomena that by their very nature occur spontaneously, and leaving almost entirely nothing but anecdotal evidence.

Trying to determine what generated the experience currently remains almost impossible to assess, as John Palmer has argued in such cases "the demonstration of psi says nothing directly about the source of the psi - in particular whether it was a discarnate entity" (see Cooper, 2012, p.171). In more recent decades, this debate has grown in popularity through the 'Super-psi hypothesis' (Braude, 1992) and what William Roll termed 'the catch-22 of survival' (Roll, 1980). Essentially, we are faced with the problem that once conventional explanations are suitably ruled out, it becomes difficult to separate instances of ESP (or other forms of psi) from survival. Further to that, ESP could be responsible for the interpretation of survival within a given experience, and by following Occam's razor, it would appear on the surface more likely to assume that the experience was generated by the living than by the surviving consciousness of the deceased. John Randall proposed that we need to work harder on trying to develop a 
method for separating one from the other, if indeed, that is at all possible (see Cooper, 2012, p. 167). Further to this debate, Storm (2006) discussed 'radical survivalism' in relation to rethinking all survival type experiences. He argued that since knowledge itself cannot be destroyed, consciousness is somehow able to dip into this pool from time to time and obtain knowledge which experients would assume was known only by the deceased. This debate in itself could be considered an extension of the super-psi hypothesis, but takes into account Jungian theory (Jung, 1960) and modern psychological thought on consciousness research in light of parapsychology (Braude, 2003; Thalbourne, 2004).

When we survey the wide array of arguments for survival (e.g. Coly \& McMahon, 1993; Gauld, 1977; Storm \& Thalbourne, 2006), there do appear to be instances where we have to make greater steps/assumptions through Occam's razor to assume ESP is responsible for the interpretation of survival if we are to accept the experience was generated on the part of the living. For example, in the case of the bereaved who witness phenomena attributed to the deceased, their conscious knowledge of personal loss and the symptoms of mourning, have been argued as responsible for creating the events (e.g. Baker, 1996). However, survival becomes more of a greater possible conclusion when the experient does not discover until after the anomalous event that the person they envisioned was dead at the time of that experience. Such a case would not constitute a bereavement encounter, given that the experient has no conscious knowledge of being in loss. Therefore, if we consider survival evidence presented only within the context of bereavement, further conventional psychological explanations begin to pile up and move the possibility of survival further away. These explanations could especially include misinterpretation of events and false memory, which are the typical sceptical assumptions we may first investigate. 
Suddoth (2016) has presented a detailed philosophical critique of the typical arguments in favour of survival. In short, it was concluded by him that in many accounts argued as evidence for survival, it might be the case that these are genuine examples of survival, however, when examining them against classical arguments they do not appear to constitute evidence for survival at all, or at least not good evidence. Cases can be discovered to have pitfalls against the existing classical theories for survival which lead to alternative explanations, and can often fall within the remit of currently understood paradigms. Suddoth concludes that a good empirical argument for survival is not impossible, but we do not currently possess one, based on the kinds of research data that is presently available. This would further emphasis John Randall's point (see Cooper, 2012, p.167) and also that of Storm (2006), in that now is the time to refine what we know about evidence we label as survival, and develop a better experimental system for assessing the data and what would truly constitute survival without room for alternative explanations. It is perhaps the case that the more we begin to understand about consciousness itself, the more likely this process of refining the assessment for survival is to become.

\section{Conclusion}

In this chapter, the commonality and general features of spontaneous anomalous experiences during a time of bereavement have been briefly defined and outlined. From there, examples of experiences suggestive of survival of death were also discussed, namely being instances of veridical information being received during the experience from the perceived deceased, or multiple witnesses to the event. In very briefly considering some of the key thoughts on survival, it is evident that it is neither clear, nor agreed upon, throughout scientific inquiry into such events, as to what would truly constitute as empirical evidence for survival. Although the two demands put forth have been demonstrated in many cases, with no apparent conventional 
explanations for their occurrence, there is still room in some cases for alternative theoretical assumptions to account for the phenomenon. Therefore, it is possible that spontaneous anomalous experiences during bereavement can be instances of the surviving personality of the deceased, contacting a bereaved living individual. How we go about objectively demonstrating this is still beyond the realms of current scientific understanding, and stands shoulder to shoulder with the hard problem of consciousness.

\section{References}

Baird, A.T. (Ed.)(1944). One hundred cases for survival after death. New York: Bernard Ackerman.

Baker, R.A. (1996). Hidden memories: Voices and visions from within. New York: Prometheus Books.

Berger, A.S. (1988). Evidence of life after death: A casebook for the tough-minded. Springfield, IL: Charles C. Thomas Pub.

Betty, S. (2016). When did you ever become less by dying? Afterlife: The evidence. Hove: White Crow Books.

Braude, S.E. (1992). Survival or Super-psi? Journal of Scientific Exploration, 6, 127-144.

Braude, S.E. (2003). Immortal remains: The evidence for life after death. New York: Rowan and Littlefield.

Burton, J. (1980). Survivors' Subjective Experiences of the Deceased. Unpublished doctoral thesis, International College, Los Angeles, CA.

Burton, J. (1982). Contact with the dead: A common experience? Fate, 35 (4), 65-73.

Castelnovo, A., Cavallotti, S., Gambini, O., \& D’Agostino, A. (2015). Post-bereavement hallucinatory experiences: A critical overview of population and clinical studies. Journal of Affective Disorders, 186, 266-274.

Coly, L., \& McMahon, J.D.S. (Eds.) (1993). Parapsychology and thanatology: Proceedings of an international conference. New York: Parapsychology Foundation.

Cooper, C.E. (2012). Telephone calls from the dead: A revised look at the phenomenon thirty years on. Old Portsmouth: Tricorn Books. 
Cooper, C.E. (2016). The therapeutic nature of anomalous events: A union of positive psychology and parapsychology. In M.D. Smith, \& P. Worth (Eds.) $2^{\text {nd }}$ Applied Positive Psychology Symposium: Proceedings of Presented Papers (pp. 98-107). High Wycombe: Bucks New University.

Cooper, C.E. (2017). Spontaneous post-death experiences and the cognition of hope: An examination of bereavement and recovery. Unpublished doctoral thesis, University of Northampton, Northampton, UK.

Cooper, C.E., Roe, C.A., \& Mitchell, G. (2015). Anomalous experiences and the bereavement process. In T. Cattoi, \& C. Moreman (Eds.) Death, Dying and Mysticism: The Ecstasy of the End (pp.117-131). New York: Palgrave Macmillan.

Fontana, D. (2005). Is there an afterlife? A comprehensive overview of the evidence. Blue Ridge Summit, PA: O-Books.

Fontana, D. (2007). Why the opposition to evidence for survival? Network Review, 93, 3-6.

Gauld, A. (1977). Discarnate survival. In B.B. Wolman (Ed.), Handbook of parapsychology (pp.577-630). New York: Van Nostrand Reinhold Co.

Gauld, A. (2005). Survival. In J. Henry (Ed.) Parapsychology: Research on exceptional experiences (pp. 215-223). London: Routledge.

Gauld, A. (2010). Reflections. Mindfield, 2 (1), 6-7.

Gurney, E., with Myers, F.W.H. (1889). On apparitions occurring soon after death. Proceedings of the Society for Psychical Research, 5, 403-485.

Gurney, E., Myers, F.W.H., \& Podmore, F. (1886). Phantasms of the living (2 vols.). London: Trübner.

Horn, S. (2009). Unbelievable. New York: HarperCollins.

Jung, C.G. (1960). The structure and dynamics of the psyche. Princeton, NJ: Princeton University Press.

Kramer, W. H., Bauer, E., and Hövelmann, G. H., (Eds.)(2012). Perspectives of clinical parapsychology. Bunnik: Stichting Het Johan Borgman Fonds.

Krippner, S. (2006). Getting through the grief: After-death communication experiences and their effects on experients. In L. Storm, \& M.A. Thalbourne (Eds.) The survival of human consciousness (pp.174-193). London: McFarland \& Co.

Martínez-Taboas, A. (1983). Uses and abuses of Occam's razor in parapsychology. Journal of the Society for Psychical Research, 52, 128-132. 
McAdams, E.E., \& Bayless, R. (1981). The case for life after death: Parapsychologists look at the evidence. Chicago, IL: Nelson-Hall.

Murphy, G. (1943). Spontaneous telepathy and the problem of survival. Journal of Parapsychology, 7, 50-60.

Myers, F.W.H. (1903). Human personality and its survival of bodily death (2 vols.). London: Longmans \& Co.

Rao, K.R. (1986). L.E. Rhine on psi and its place. In K.R. Rao (Ed.), Case studies in parapsychology in honor of Dr. Louisa E. Rhine (pp. 52-62). Jefferson, NC: McFarland \& Co.

Rees, W.D. (1971). The hallucinations of widowhood. British Medical Journal, 4, 37-41.

Rees, W.D. (2000). The bereaved and the dead. Christian Parapsychologist, 14 (3), 81-86.

Robertson, T.J. (2013). Things you can do when you're dead: True accounts of after death communication. Guildford: White Crow Books.

Rogo, D.S. (1986). Life after death: The case for survival of bodily death. London: Guild Pub.

Roll, W.G. (1980). The catch 22 of survival research. Journal of the Academy of Religion and Psychical Research, 3, 23-24.

Romer, C. (1996). The poverty theory: Notes on the investigation of spontaneous cases. Journal of the Society for Psychical Research, 62, 161-163

Roxburgh, E., \& Evenden, R. (2016). 'They daren't tell people': Therapists' experiences of working with clients who report anomalous experiences. European Journal of Psychotherapy \& Counselling, 18 (2), 123-141.

Smith, M.D. (2010). Preface. In M.D. Smith (Ed.) Anomalous experiences: Essays from parapsychological and psychological perspectives (pp. 1-4). Jefferson, NC: McFarland.

Steffen, E., Wilde, D., \& Cooper, C.E. (in press). Affirming the positive in anomalous experiences: A challenge to dominant accounts of reality, life and death. In N.J.L. Brown, T. Lomas, \& F.J. Eiroá (Eds.) International Handbook of Critical Positive Psychology: A Synthesis for Social Change. London: Routledge.

Storm, L. (2006). A solution: Radical survivalism. In L. Storm, \& M.A. Thalbourne, (Eds.), The survival of human consciousness: Essays on the possibility of life after death (pp. 285300). Jefferson, NC: McFarland.

Storm, L., \& Thalbourne, M.A. (Eds.) (2006). The survival of human consciousness: Essays on the possibility of life after death. Jefferson, NC: McFarland. 
Sudduth, M. (2016). A philosophical critique of empirical arguments for post-mortem survival. New York: Palgrave.

Thalbourne, M.A. (2004). The common thread between ESP and PK. New York:

Parapsychology Foundation.

Thomas, J.F. (1929). Case studies bearing upon survival. Boston: Boston Society for Psychic Research.

Thomas, K., \& Cooper, C.E. (2016). Investigation of viewer opinions on the use of "science" in paranormal reality television shows. Paper presented at the $40^{\text {th }}$ International Conference of the Society for Psychical Research, University of Leeds, Leeds, UK.

Weiner, D.H., \& Haight, J. (1986). Charting hidden channels: Louisa E. Rhine's case collection project. In K.R. Rao (Ed.), Case studies in parapsychology in honor of Dr. Louisa E. Rhine (pp. 14-30). Jefferson, NC: McFarland \& Co.

Winsper, A.R., Parsons, S.T., \& O'Keeffe, C.J. (2008). Have the lunatics taken over the (haunted) asylum? Paper presented at the $32^{\text {nd }}$ International Conference of the Society for Psychical Research held jointly with the Parapsychological Association, University of Winchester, Winchester, UK.

Wright, S.H. (1998). Experiences of spontaneous psychokinesis after bereavement. Journal of the Society for Psychical Research, 62, 385-395. 